\title{
Estimating Binding Capability of Radiopharmaceuticals by Cell Culture Studies
}

\section{Derya İlem-Özdemir*, Meliha Ekinci, Evren Gündoğdu and Makbule Aşıkoğlu}

\author{
Department of Radiopharmacy, Ege University, Turkey
}

*Corresponding author: Derya Illem-Özdemir, Faculty of Pharmacy, Department of Radiopharmacy, Ege University, 35100 Bornova, Izmir, Turkey, Tel: +90-533-446-40-26, Fax: +90-232-388-52-58, E-mail: deryailem@gmail.com

\begin{abstract}
Radiopharmaceuticals have applications in biologic research, drug discovery, diagnosis of human disease and molecular therapeutics for a wide variety of medical conditions. With the increasingly central role of radiotracers for non-invasive imaging of animal models and human research, small animal imaging centers are likely to have a growing interest in development of radiopharmaceutical science. Although animal experiments are giving the most valuable information about the drug behavior in the biological system. Also every year, millions of experimental animals are used all over the world. The pain, distress and death experienced by the animals during scientific experiments have been a debating issue for a long time.

Use of cell culture techniques play a key role in new drug development studies by giving information about receptor interaction, drug uptake/efflux or interaction with other cellular receptors and cellular metabolism.

This review will focus on how cell culture techniques are able to use to estimate the uptake of developed radiopharmaceutical by targeted receptor-bearing cells.
\end{abstract}

\section{Keywords}

Radiopharmaceuticals, Cell culture, Receptor-bearing cells Incorporation study

\section{Introduction}

\section{Radiopharmaceuticals in medicine}

The history of nuclear medicine over the past 50 years highlights the strong link between investments in chemistry and the development of radionuclides and radiolabeled compounds [1]. Radiopharmaceuticals are drugs containing radioisotopes which are safe for administration in humans for diagnosis or therapy. The use of radiopharmaceuticals for imaging organ function and disease states is a unique capability of nuclear medicine. Unlike other imaging modalities nuclear medicine imaging is an excellent non-invasive method of whole-body scanning, based on pathophysiological and pathobiological changes which occur in the earlier process $[2,3]$.

The mapping of the radiopharmaceutical distribution in vivo provides images of functional morphology of organs in a noninvasive manner and plays an important role in the diagnosis of many common diseases associated with the malfunctioning of organs in the body as well as in the detection of certain type of cancers [4].
Radiopharmaceuticals have applications in biologic research, drug discovery, diagnosis of human disease and molecular therapeutics for a wide variety of medical conditions. With the increasingly central role of radiotracers for non-invasive imaging of animal models and human research, small animal imaging centers are likely to have a growing interest in development of radiopharmaceutical science [5]. Although animal experiments are giving the most valuable information about the drug behavior in the biological system, to justify the high cost of the current dedicated preclinical scanners [6].

There are few more disadvantages of animal experimentation like requirement of skilled manpower, time consuming protocols and high cost. Also every year, millions of experimental animals are used all over the world. The pain, distress and death experienced by the animals during scientific experiments have been a debating issue for a long time. However non-animal models cannot completely eliminate the use of animals in testing various methods has been suggested to avoid the animal use in experimentation. These methods such as computer models, alternative organisms, cells and tissue cultures provide an alternative means for the drug and chemical testing, up to some levels $[7,8]$.

\section{In-vitro cell culture studies}

Use of in vitro cell and tissue cultures which involves growth of cells outside the body in laboratory environment can be an important alternative for animal experiments. Cell culture techniques play a key role in new drug development studies by giving information about receptor interaction, drug uptake/efflux or interaction with other cellular receptors and cellular metabolism [9]. Targeted drug delivery systems promise to expand the therapeutic windows of drugs by increasing the delivery to the target tissue. This will in turn lead to reduction in the minimum effective dose of the drug and the accompanying drug toxicity, and improvement in therapeutic efficacy at equivalent plasma concentration [10]. Likewise the conventional drugs since the utility of a radiopharmaceutical is dependent upon the achievement of adequate ratios of target to non-target accumulation ratio, the development of receptor specific radiopharmaceuticals is a useful approach to design. Therefore the success of the developed radiopharmaceuticals is depending on the high affinity and binding specificity for the receptor [10-12]. Cell culture techniques can make significant contributions in the early stage of drug discovery and development for radiopharmaceuticals.

Many researchers prefer to use cultured tumor cells, to evaluate 


\section{$\square+$}

Radiolabeling

Labeled Compound

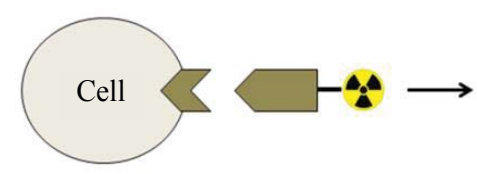

Incubation With Cell

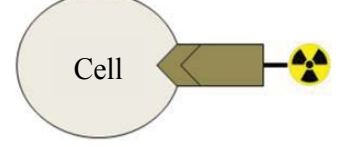

Cell Incorporation

Figure 1: Basic scheme of radiopharmaceuticals cell incorporation study.

the uptake of developed radiopharmaceutical by targeted receptorbearing cells. Cell culture studies which perform to evaluate the specificity of radiopharmaceuticals are performing in two stages (Figure 1).

Mostly receptor specific oncological radiopharmaceutical's imaging capability investigates by cell culture studies. The membrane-associated folate receptor is a tumor marker that is over expressed on a variety of neoplastic tissues, including breast, cervical, ovarian, colorectal, renal and nasopharyngeal tumors, but highly restricted in most normal tissues agents. Therefore, folate receptor system is a valuable target for selective drug delivery systems [4,13-17]. Since folic acid conjugates have been shown to bind the folate receptors with high affinity and are taken up by tumor cells via folate receptor mediated endocytosis, folate conjugation is a useful method for receptor mediated drug delivery to receptor positive tumor cells [18-20].

Cell culture studies are performed with cell culture protocols. To concentrate cells from a suspension culture (or resuspended cells from monolayer culture):

1. Transfer the cell suspension to a sterile centrifuge tube of appropriate size and centrifuge for 10 minutes at $800 \times \mathrm{g}$.

2. Carefully remove the supernatant without disturbing the cell pellet.

3. Add the desired volume of fresh medium gently to the side of the tube and slowly pipette up and down 2 to 3 times to resuspend the cell pellet.

4. Transfer the cells to the desired, sterile container.

To count cells in a hemacytometer: Hemacytometers may be obtained from most major laboratory suppliers [e.g., Baxter Scientific]. The procedure below provides some general directions on how to use the hemacytometer.

1. Clean the chamber and cover slip with alcohol. Dry and fix the coverslip in position.

2. Harvest the cells. Add $10 \mu \mathrm{L}$ of the cells to the hemacytometer. Do not overfill.

3. Place the chamber in the inverted microscope under a $10 \mathrm{X}$ objective. Use phase contrast to distinguish the cells.

4. Count the cells in the large, central gridded square $\left(1 \mathrm{~mm}^{2}\right)$. The gridded square is circled in the graphic below. Multiply by $10^{4}$ to estimate the number of cells per $\mathrm{mL}$. Prepare duplicate samples and average the count.

Subculturing, also referred to as passaging, is the removal of the medium and transfer of cells from a previous culture into fresh growth medium, a procedure that enables the further propagation of the cell line or cell strain. The criteria for determining the need for subculture are similar in adherent and suspension cultures; however, there are some differences between mammalian and insect cell lines [21].
Cell cultures are generally immortalized or transformed cells. That means that the cell has lost the control of not divide more than certain amount of times. That could be because there were mutations or genetic alterations that lead to that lack of control, or because a primary cell was transfected with some genes immortalizing the cells. Most cell lines come from tumors. Primary cell lines don't have those issues, but they are much more difficult to take care off. Usually, primary cell cultures need a richer mixture of aminoacids and micronutrients, sometimes, some type of hormones or growth factors. Primary cultures are useful within the first few passages, usually within passage $2-4$. The risk of contamination is higher than for cell lines. But the one advantage is that the biological response may be closer to an in vivo situation than the one obtained with cell lines. There are several cell lines which have been tested for years, under different conditions, and there is good amount of data supporting the use of specific cell lines as models of primary cells.

Furthermore, IC50 or kD-studies in cell culture, internalization, externalization (retention) studies are absolutely necessary for a very first characterization of the binding behavior of a new tracer; but will never give a more that a very preliminary picture of the real in vivo situation (metabolism and formed species, specific uptake in other tissues, unspecific uptake, clearance kinetics, clearance route, retention in (excretion, but also other) organs, plasma protein binding, uptake by blood cells, penetration of the blood brain barrier...).

\section{In-vitro evaluation of radiopharmaceuticals to target folate receptors}

Many researchers were performed studies to investigate new radiopharmaceuticals for folate receptor positive tumor imaging or therapy [20-26]. While some of those performed in vivo imaging studies with tumor model created mice, others investigate receptor positive tumor cell affinity by cell culture studies.

Recent studies showed that in tumor tissue folate receptors were found higher compared with healthy tissue such as breast tumor. The membrane-associated folate receptor is a tumor marker and when folate is covalently linked to a molecule via its $\gamma$-carboxyl moiety, its affinity for its cell surface receptor remains essentially unaltered. To evaluate the potential of a radiolabeled folate conjugate in tumor diagnostic imaging, the metal chelator deferoxamine $[\mathrm{DF}]$ was linked to folic acid, labeled with ${ }^{67} \mathrm{Ga}$, and imaging was performed in an athymic mouse tumor model $[27,28]$. Although the authors obtained very high tumor uptake, it was also shown that approximately $30 \%$ of the drug was excreted via the hepatobiliary route which makes clearance rate through the gastrointestinal tract a major factor in determining the time of abdominal tumors.

Wang et al. designed and synthesized [ $\left.{ }^{111} \mathrm{In}\right]$ DTPA-Folate as a tumor targeted radiopharmaceutical with the aim to be cleared more rapidly and selectively from the body into the urine [29]. According to this study, uptake of [ ${ }^{111} \mathrm{In}$ ] DTPA-Folate was found to be specific for folate receptor-bearing cells. Also in a preliminary mouse imaging study, a folate receptor positive cell tumor was readily visualized by $\gamma$ scintigraphy $1 \mathrm{~h}$ following intravenous administration. The authors prove the ability of [ $\left.{ }^{111} \mathrm{In}\right]$ DTPA-folate to target folate receptors with both cell culture and in vivo studies [29].

Methotrexate (MTX), is an analogue of folic acid, which exhibits not only a targeting role as folic acid but also a therapeutic effect to many types of cancer cells that over express folate receptors on their surfaces. Ozgenc et al. radiolabeled MTX with ${ }^{99 \mathrm{~m}} \mathrm{Tc}$ in a simple radiochemical method and investigated incorporation of ${ }^{99 \mathrm{~m}} \mathrm{Tc}-\mathrm{MTX}$ to human breast (CRL8798) and human breast carcinoma (MCF7) cell lines [30]. According to this study, the cell incorporation percentage after the application of ${ }^{99 \mathrm{~m}} \mathrm{Tc}$-MTX were found to be between $38.2 \pm 4.49 \%$ and $56.7 \pm 0.64 \%$ for CRL8798 and MCF7 cell lines, respectively. The authors conclude that, due to have a greater incorporation activity on MCF-7 than CRL8798, ${ }^{99 \mathrm{~m}} \mathrm{Tc}$-MTX can be candidate for breast cancer diagnosis, offering potential for developing new selective therapies for this resilient cancer. 
Trump et al. prepared a folate-receptor-targeted ${ }^{99 \mathrm{~m}} \mathrm{Tc}$ radiopharmaceutical, [99m $\mathrm{Tc}] \mathrm{Tc}(\mathrm{CO})_{3} \mathrm{DTPA}$-folate, and evaluated in vitro and in vivo as an agent for targeting folate-receptor-positive cells. According to this study, developed radiopharmaceutical has high affinity to folate-receptor-specific uptake in human oral carcinoma KB cells and after intravenous administration to athymic mice bearing $\mathrm{KB}$ cell tumor xenografts resulted in tumor uptake of $1.8 \pm 0.5$ and $3.3 \pm 0.2 \% \mathrm{ID} / \mathrm{g}[n=3]$ at $30 \mathrm{~min}$ and $4 \mathrm{~h}$ post-injection, respectively. The authors conclude that, as a folate-receptor-targeted radiopharmaceutical, [99m $\mathrm{Tc}] \mathrm{Tc}(\mathrm{CO})_{3} \mathrm{DTPA}$-folate does not appear to offer advantages over other folate-chelate conjugates, due to the levels of radiotracer in non-target tissues [22].

In addition to folate receptors, there are also examples which containing plants. In a study, Plumbagin (PL) that is a plant origin product, has various biological activities like anticancer activity and specificity to estrogen receptor (ER), was used. Yurt Kilcar et al. radiolabeled $\mathrm{PL}$ and investigated in vitro studies on $\mathrm{ER}^{+}$and $\mathrm{ER}^{-}$adeno carcinoma cells [31]. Additionally, poly (D,L-lactide)-coglycolide (PLGA) encapsulation was carried out to reduce toxicity of PL and encapsulation effect was investigated. MCF-7 $\left(\mathrm{ER}^{+}\right)$and MDAMB-231 (ER') breast adeno carcinoma epithelial cell lines were used during cell incorporation study. ${ }^{99 \mathrm{~m}} \mathrm{Tc}-\mathrm{PL},{ }^{99 \mathrm{~m}} \mathrm{Tc}$-PL-PLGA and ${ }^{99 \mathrm{~m}} \mathrm{Tc}$ were applied to the cells, separately. Incorporation of ${ }^{99 \mathrm{~m}} \mathrm{Tc}$ labeled PL and PL-PLGA on MCF- 7 and MDA-MB-231 cells were investigated at different time intervals [30, 60, 120 and $240 \mathrm{~min}]$. After incubation; initial radio activities of the cells were measured, after initial measurement cells were washed three times with PBS and final radio activities of the cells were measured. According to the results of the study was PL radiolabeled by ${ }^{99 \mathrm{~m}} \mathrm{Tc}$ with $100 \%$ labeling yield and had ER specificity. Furthermore, PLGA encapsulation effected positively on properties of PL; reduced toxicity, increased stability and ER specificity. So, the authors conclude the PL has a favorable potential on ER specific breast cancer diagnosis and PLGA encapsulation has a positive effect on this potential increasing its ER specificity. Therefore, within the naturally occurring naphthoquinones PL, as a promising anticancer agent will necessitate further deep investigation for a probable use for diagnosis of ER+ breast cancer.PL as a promising agent for the diagnosis of $\mathrm{ER}^{+}$breast cancer [31].

\section{In-vitro Evaluation of Radiopharmaceuticals to Drug to a Specific Cancer Cell}

Drug delivery approaches by using nanoparticles (NPs) have additional advantage of specificity which means targeting drug to a specific cancer cell. Akman et al. designed a compound, which has fluorescence capability, nano capsulated structure, included an anticancer drug for targeting and radionuclidic tracer content for tracing may be used theranostic purposes on some types of cancer cell lines. For this purpose, indocyanine loaded PEGylated poly (lactic-co-glycolic acid) which is designed as multi-functional biodegradable and biocompatible nanocapsules including an optical imaging contrast agent for cancer imaging and as a photothermal therapy agent was developed and characterized. Final product was radiolabeled with ${ }^{131} \mathrm{I}$ for radionuclidic tracing in the tissues. In vitro incorporation and cell viability studies were performed with HeLa (cervix adenocarcinoma) and MCF- 7 epithelial cell lines. According to the studies, florescence microscopy demonstrated that newly developed formulations successfully incorporated to the cancer cells. The authors conclude that, further investigation using animal models may be needed to examine the feasibility of indocyanine loaded PAC [32].

Gundogdu et al. published an article to investigate cell binding on normal and cancer cells of NPs which contain hydrophilic materials such as chitosan (CS) and to explore their potential for tissue targeting. For this purpose, the authors developed radiolabeled CSNPs by ${ }^{99 \mathrm{~m}} \mathrm{Tc}$ with high labeling yield in the presence of stannous chloride agents. Radiolabeled CSNPs were proven as a useful tool for assessing the in vitro incorporation studies for normal and cancer cell lines. The results of the study indicate more incorporating into the cancer cell lines. Therefore the authors conclude that ${ }^{99 \mathrm{~m}} \mathrm{Tc}$ labeled CSNPs can be candidate for cancer diagnosis [33].
Also Ekinci et al. developed radiolabeled MTX loaded nanoparticulate systems for breast cancer imaging [26]. The researchers evaluated the binding affinity of the newly developed formulation to cancer cells by cell culture incorporation studies. As part of the cell culture studies, the incorporation of ${ }^{99 \mathrm{~m}} \mathrm{Tc}$-MTX loaded NPs to normal and cancer cell lines was evaluated in MCF-7 and human keratinocyte (HaCaT) cell lines. Their results demonstrated that the incorporation of ${ }^{99 \mathrm{~m}} \mathrm{Tc}-\mathrm{MTX}$ loaded NPs in breast cancer cells was found about 2-times higher than normal cells. The authors conclude that, due to the high incorporation for breast cancer cell line, newly developed formulation may be used for breast cancer diagnosis in nuclear medicine center [26].

Over the last decades bone scintigraphy has been used extensively in the evaluation of oncological patients to provide information about the sites of bone lesions, their prognosis and the effectiveness of therapy by showing the sequential changes in tracer uptake. Since the lesion visualization and lesion/bone ratio are important utilities for a bone scanning. Gundogdu et al. published an article to investigate the cell binding of ${ }^{99 \mathrm{~m}} \mathrm{Tc}$ labeled alendronate sodium $\left({ }^{99 \mathrm{~m}} \mathrm{Tc}-\mathrm{ALD}\right)$ in $\mathrm{U}_{2} \mathrm{OS}$ (human bone osteosarcoma) and NCI-H209 (human bone carcinoma) cell lines. Results of the study confirmed that ALD was successfully radiolabeled with ${ }^{99 \mathrm{~m}} \mathrm{Tc}$ and ${ }^{99 \mathrm{~m}} \mathrm{Tc}$-ALD incorporated with NCI-H209 and $\mathrm{U}_{2} \mathrm{OS}$ cells. Furthermore, the uptake percentages of ${ }^{99 \mathrm{~m}} \mathrm{Tc}$-ALD in NCI-H209 and $\mathrm{U}_{2} \mathrm{OS}$ cell lines were found significantly higher. Since ${ }^{99 \mathrm{~m}} \mathrm{Tc}$-ALD highly uptake in cancer cell line, the authors conclude that radiolabeled ALD may be a promising agent for bone cancer diagnosis [34].

Various malignant tumor cells express neuropeptide receptors on their surface in much higher concentration than most healthy tissues [35]. Thus, these over expressed receptors could be used as potential targets for imaging and therapy with radiolabeled neuropeptides such as bombesin, cholecystokinin andneurotensin [36-39]. Thus, the interest for an application of radiolabeled neuropeptides analogues in nuclear medicine has rapidly increased. La Bella et al. synthesized, in vitro and in vivo characterized the [ ${ }^{99 \mathrm{~m}} \mathrm{Tc}(\mathrm{I})-\mathrm{PADA}-$ AVA] bombesin as a new radiopharmaceutical for diagnosis of GRP receptor over expressing tumors. Cell culture studies were performed and high affinity and rapid internalization were obtained in binding assays. Therefore the authors conclude that [ $\left.{ }^{99 \mathrm{~m}} \mathrm{Tc}(\mathrm{I})-\mathrm{PADA}-\mathrm{AVA}\right]$ bombesin may be successfully used for scintigraphy of GRP receptor expressing tumors [40].

\section{Conclusion}

Research and discovery of new radiopharmaceuticals generally involve initial studies in cell cultures, followed by animal studies, both of which present several inherent limitations. Many researchers performed the cell culture studies with newly developed radiopharmaceuticals to investigate their imaging capability, cytotoxicity, receptor specificity. This review has outlined the samples of estimating imaging capability of radiopharmaceutics by cell culture studies. The current status of different radiopharmaceutics which containing folate receptor, plant, nanoparticulate systems has been evaluated the context of their application to incorporation cancer cells by using cell culture studies.

\section{References}

1. National Research Council (US) and Institute of Medicine (US) Committee on State of the Science of Nuclear Medicine. (2007) Advancing Nuclear Medicine Through Innovation. National Academies Press (US), Washington (DC).

2. van der Laken CJ, Boerman OC, Oyen WJ, van de Ven MT, van der Meer JW, et al. (1998) Scintigraphic detection of infection and inflammation: new developments with special emphasis on receptor interaction. Eur J Nucl Med 25: 535-546.

3. Becker W (1995) The contribution of nuclear medicine to the patient with infection. Eur J Nucl Med 22: 1195-1211.

4. Radiopharmaceuticals: Production and Availability.

5. Subcommittee of the Biological and Environmental Research Advisory Committee (2004) Radiopharmaceutical Development and the Office of Science. Washington. 
6. Gutfilen B, Valentini G (2014) Radiopharmaceuticals in nuclear medicine: Recent developments for SPECT and PET studies. Biomed Res Int: 3.

7. http://cfhs.ca/research/alternatives_to_animal_testing/

8. Doke SK, Dhawale SC (2015) Alternatives to animal testing: A review. Saudi Pharm J 23: 223-229.

9. Baguley BC, Hicks KO, Wilson WR (2002) Tumor Cell Cultures in Drug Development. In: Baguley BC, Kerr DJ, Anticancer Drug Development. Academic Press, Auckland, New Zealand, 269-284.

10. Sudimack J, Lee RJ (2000) Targeted drug delivery via the folate receptor. Adv Drug Deliv Rev 41: 147-162.

11. Ross JF, Chaudhuri PK, Ratnam M (1994) Differential regulation of folate receptor isoforms in normal and malignant tissues in vivo and in established cell lines. Physiologic and clinical implications. Cancer 73: 2432-2443.

12. Weitman SD, Lark RH, Coney LR, Fort DW, Frasca V, et al. (1992) Distribution of the folate receptor GP38 in normal and malignant cell lines and tissues. Cancer Res 52: 3396-3401.

13. Rettig WJ, Garin-Chesa P, Beresford HR, Oettgen HF, Melamed MR, et al (1988) Cell-surface glycoproteins of human sarcomas: differential expression in normal and malignant tissues and cultured cells. Proc Natl Acad Sci USA 85: 3110-3114.

14. Coney LR, Tomassetti A, Carayannopoulos L, Frasca V, Kamen BA, et al. (1991) Cloning of a tumor-associated antigen: MOv18 and MOv19 antibodies recognize a folate-binding protein. Cancer Res 51: 6125-6132.

15. Garin-Chesa P, Campbell I, Saigo P, Lewis JL Jr, Old LJ, et al. (1993) Trophoblast and ovarian cancer antigen LK26. Sensitivity and specificity in immunopathology and molecular identification as a folate-binding protein. Am J Pathol 142: 557-567.

16. Holm J, Hansen SI, Høier-Madsen M, Søndergaard K, Bzorek M (1994) Folate receptor of human mammary adenocarcinoma. APMIS 102: 413-419.

17. Franklin WA, Waintrub M, Edwards D, Christensen $\mathrm{K}$, Prendegrast $\mathrm{P}$, et al. (1994) New anti-lung-cancer antibody cluster 12 reacts with human folate receptors present on adenocarcinoma. Int J Cancer Suppl 8: 89-95.

18. Antony AC (1992) The biological chemistry of folate receptors. Blood 79 2807-2820.

19. Turek JJ, Leamon CP Low PS (1993) Endocytosis of folate-protein conjugates: Ultrasctructural localization in KB cells. J Cell Sci 106: 423-430.

20. Panwar P, Shrivastava V, Tandon V, Mishra P, Chuttani K, et al. (2004) $99 \mathrm{mTc}$-Tetraethylenepentamine-Folate a new $99 \mathrm{mTc}$-based folate derivate for the detection of folate receptor positive tumors:synthesis and biological evaluation. Cancer Biol Ther 3: 995-1001.

21. GIBCO, InVitrogen, (2014) Cell Culture Basics Handbook. England: 44-51.

22. Trump DP, Mathias CJ, Yang Z, Low PS, Marmion M, et al. (2002) Synthesis and evaluation of $99 \mathrm{mTc}(\mathrm{CO})(3)$-DTPA-folate as a folate-receptor-targeted radiopharmaceutical. Nucl Med Biol 29: 569-573.

23. Müller C, Schibli R (2013) Prospects in folate receptor-targeted radionuclide therapy. Front Oncol 3: 249

24. Mathias CJ, Wang S, Waters DJ, Turek JJ, Low PS, et al. (1998) Indium111-DTPA-folate as a potential folate-receptor-targeted radiopharmaceutical. J Nucl Med 39: 1579-1585.
25. Guo W, Hinkle GH, Lee RJ (1999) 99mTc-HYNIC-folate: a novel receptorbased targeted radiopharmaceutical for tumor imaging. J Nucl Med 40: 1563 1569 .

26. Ekinci M, llem-Ozdemir D, Gundogdu E, Asikoglu M (2015) Methotrexate loaded chitosan nanoparticles: Preparation, radiolabeling and in vitro evaluation for breast cancer diagnosis. J Drug Deliv Sci Technol 30: 107-113.

27. Wang S, Lee RJ, Mathias CJ, Green MA, Low PS (1996) Synthesis, purification, and tumor cell uptake of $67 \mathrm{Ga}$-deferoxamine--folate, a potential radiopharmaceutical for tumor imaging. Bioconjug Chem 7: 56-62.

28. Mathias CJ, Wang S, Lee RJ, Waters DJ, Low PS, et al. (1996) Tumor selective radiopharmaceutical targeting via receptor-mediated endocytosis: evaluation of a gallium-67 labeled deferoxamine-folate conjugate. J Nucl Med 37: 1003-1008.

29. Wang S, Luo J, Lantrip DA, Waters DJ, Mathias CJ, et al. (1997) Design and synthesis of [111/n]DTPA-folate for use as a tumor-targeted radiopharmaceutical. Bioconjug Chem 8: 673-679.

30. Ozgenc E, Ekinci M, llem-Ozdemir D, Gundogdu E, Asikoglu M (2015) Radiolabeling and in vitro evaluation of $99 \mathrm{mTc}$-methotrexate on breast cancer cell line. J Radioanal Nucl Chem.

31. Yurt Kilcar A, Tekin V, Biber Muftuler FZ, Medine El (2015) ${ }^{99 \mathrm{~m} T c}$ labeled plumbagin: estrogen receptor dependent examination against breast cance cells and comparison with PLGA encapsulated form. J Radioanal Nucl Chem: $1-10$

32. Akman L, BiberMuftuler FZ, Bilgi A, Yurt Kilcar A, GoksunGokulu S, et al. (2015) Synthesis of a theranostic agent: radioiodinated PEGylated PLGAindocyanine capsules and in vitro determination of their bioaffinity on ovarian, cervical and breast cancer cells. J Radioanal Nucl Chem.

33. Gundogdu E, llem-Ozdemir D, Ekinci M, Ozgenc E, Asikoglu M (2015) Radiolabeling efficiency and cell incorporation of chitosan nanoparticles. $J$ Drug DelivSciTechnol 29: 84-89.

34. Gundogdu E, Ilem-Ozdemir D, Asikoglu M (2014) In vitro incorporation studies of $99 \mathrm{mTc}$ - alendronate sodium at different bone cell lines. J Radioanal Nucl Chem 299: 1255-1260.

35. Fischman AJ, Babich JW, Strauss HW (1993) A ticket to ride: peptide radiopharmaceuticals. J Nucl Med 34: 2253-2263.

36. Breeman WA, Hofland LJ, de Jong M, Bernard BF, Srinivasan A, et al (1999) Evaluation of radiolabelled bombesin analogues for receptor-targeted scintigraphy and radiotherapy. Int J Cancer 81: 658-665.

37. Karra SR, Schibli R, Gali H, Katti KV, Hoffman TJ, et al. (1999) 99mTclabeling and in vivo studies of a bombesin analogue with a novel watersoluble dithiadiphosphine- based bifunctional chelating agent. Bioconjug Chem 10: 254-260.

38. Reubi JC (1997) Regulatory peptide receptors as molecular targets for cancer diagnosis and therapy. Q J Nucl Med 41: 63-70.

39. Safavy A, Khazaeli MB, Qin H, Buchsbaum DJ (1997) Synthesis of bombesin analogues for radiolabeling with rhenium-188. Cancer 80: 2354-2359.

40. La Bella R, Garcia-Garayoa E, Langer M, Bläuenstein P, Beck-Sickinger AG et al. (2002) In vitro and in vivo evaluation of a $99 \mathrm{mTc}(\mathrm{I})$-labeled bombesin analogue for imaging of gastrin releasing peptide receptor-positive tumors. Nucl Med Biol 29: 553-560. 